\title{
Effects of a 90-min educational intervention for patients with insect venom allergy: a prospective controlled pilot study
}

Lisa-Sophie Schoeben ${ }^{1}$, Nicole Mohr ${ }^{2}$, Corinna Bubak ${ }^{1}$, Astrid Schmieder ${ }^{1}$ and Marthe-Lisa Schaarschmidt ${ }^{*}$ (0)

\begin{abstract}
Background: Anaphylactic sting reactions need a prompt management. A structured educational intervention for patients with insect sting allergy has not been implemented so far. The purpose of this study was to analyze the effects of a structured 90-min educational intervention for patients with insect sting allergy.

Methods: Patients with an insect venom allergy were offered to participate in a structured 90-min group education (intervention group (IG)) or to attend a control group (CG). The patients' subjective self-assurance in using the emergency medication, the willingness to always carry the emergency medication, the mental health status, absolute one-time willingness-to-pay (WTP) for complete cure, a disease knowledge assessment and a simulation test to examine the ability to manage an acute sting reaction were estimated at baseline (t0) and at follow-up (t1) as outcome parameters.
\end{abstract}

Results: 55 patients participated in the IG ( $n=25,52.0 \%$ female, mean age 55.9 years) or the CG $(n=30,56.7 \%$ female, mean age 52.0 years). Both arms showed a significant gain in self-assurance in using the emergency medication (IG: 6.1 at t0 vs. 8.6 at t1, $p<0.0001$ and CG: 7.1 vs. 8.0, $p=0.0062$ ) and ability to manage an acute sting reaction (IG: 6.7 vs. 11.4, $p<0.0001$ and CG: 9.0 vs. 10.5, $p=0.0002$ ) at t1. However, trained participants showed a significantly higher gain in the respective parameters. There were no significant changes regarding the remaining examined outcome parameters.

Conclusions: Patients who are willing to invest $90 \mathrm{~min}$ in a patient education intervention benefit significantly by an increased subjective and objective empowerment to manage an acute sting reaction.

Keywords: Anaphylaxis, Emergency medication, Insect venom allergy, Patient education, Emergency management

\section{Background}

Anaphylaxis is a clinical emergency of rapid onset with symptoms of an immediate-type allergic reaction [1]. Clinical features range from mere skin involvement to mild, moderate or severe, life-threatening systemic symptoms according to the German S2-guideline for

\footnotetext{
${ }^{*}$ Correspondence: marthe-lisa.schaarschmidt@umm.de

1 Department of Dermatology, University Medical Center Mannheim,

Heidelberg University, Theodor-Kutzer-Ufer 1-3, 68135 Mannheim, Germany

Full list of author information is available at the end of the article
}

acute therapy and management of anaphylaxis [1]. However, allergic reactions are not only physically frightening but may also cause a psychological burden [2]. In adults, one of the most common causes of anaphylaxis are insect stings [3, 4]. Even though fatal sting reactions are infrequently reported, several sting fatalities may be unrecognised and attributed to other causes [5]. In untreated adults with a history of systemic sting reactions, a repeated sting causes another systemic reaction in about $30-65 \%$ of cases [6]. Therefore, all patients with a history of a previous systemic allergic reaction triggered by a stinging insect should receive the original author(s) and the source, provide a link to the Creative Commons licence, and indicate if changes were made. The images or other third party material in this article are included in the article's Creative Commons licence, unless indicated otherwise in a credit line to the material. If material is not included in the article's Creative Commons licence and your intended use is not permitted by statutory regulation or exceeds the permitted use, you will need to obtain permission directly from the copyright holder. To view a copy of this licence, visit http://creativecommons.org/licenses/by/4.0/. The Creative Commons Public Domain Dedication waiver (http://creativeco mmons.org/publicdomain/zero/1.0/) applies to the data made available in this article, unless otherwise stated in a credit line to the data. 
information about how to avoid a re-sting and how to recognize anaphylaxis. Furthermore, the indication for venom immunotherapy (VIT) needs to be assessed by a specialist [7].

Acute sting reactions need prompt management. Thus, all patients who survived an anaphylaxis episode and cannot avoid with certainty the elicitor should be prescribed an "emergency set for self-help "(in Germany, Austria and Switzerland commonly the following drugs are included: epinephrine auto-injectors (EAI), oral $\mathrm{H} 1$-antihistamines and oral glucocorticoids) and should be advised to carry it with them [1]. Moreover, an adequate instruction about how to correctly use the kit for self-treatment is of particular importance and patients must understand that using the kit is not a substitute for emergency medical attention (in case of biphasic or protracted anaphylaxis) [1, 4]. Summing up, given the serious consequences for untreated anaphylactic reactions or the misuse of the emergency medication, adequate patient education regarding anaphylaxis is crucial. However, poor knowledge on how to use the emergency kit and poor compliance in carrying the emergency medication have been frequently reported [8-10] and the need for better patient education is repeatedly highlighted [7-16].

Interestingly, Brockow et al. investigated the effects of a structured patient education intervention on patients with previous episodes of anaphylaxis and caregivers of affected children [17]. The two 3-h schooling modules of group education had a significant impact on patient knowledge, increased their emergency management competence and reduced caregiver anxiety. The most common trigger for anaphylaxis was food in their study cohort. Based on those findings, we suggested that a shorter patient education specifically addressing patients with insect sting allergy may be beneficial, too.

With the presented prospective pilot study, we evaluated whether a 90-min group-based educational program especially for patients with insect sting allergy also has a positive effect.

\section{Methods}

\section{Patients}

The study was conducted at the Department of Dermatology, Venereology and Allergology at the University Medical Center Mannheim, Germany from $04 / 2016$ to $01 / 2017$. The division for Allergology offers diagnostic workup and VIT for patients with insect sting allergy. Every patient with a history of an anaphylactic sting reaction receives non-standardized short oral and written instructions on how to avoid stings and how to use the emergency medication as well as a practical demonstration of the EAI with a training device once at the first visit. The explanation and demonstration take approximately $5 \mathrm{~min}$.

All patients visiting the department because of an anaphylactic insect sting reaction were asked to participate in the study. Inclusion criteria comprised age $\geq 18$ years and diagnosis of an anaphylactic reaction after an insect sting confirmed by an allergist (defined as a history of insect venom-related anaphylaxis and evidence of immunoglobulin E (IgE)-mediated sensitization to the insect). The routine diagnostic workup included skin tests (skin prick testing (venom concentrations of $1.0 \mu \mathrm{g} /$ $\mathrm{mL}, 10 \mu \mathrm{g} / \mathrm{mL}$ and $100 \mu \mathrm{g} / \mathrm{mL}$ ) and if skin prick testing is negative intradermal testing (venom concentrations of $0.01 \mu \mathrm{g} / \mathrm{mL}, 0.1 \mu \mathrm{g} / \mathrm{mL}$, and $1.0 \mu \mathrm{g} / \mathrm{mL}$ )) and measurement of specific IgE. Only if the aforementioned tests were all negative but there was an unequivocal history of insect venom-related anaphylaxis the basophil activation test was used. A sensitization was considered verified, if skin test and/or laboratory tests were positive. An exclusion criterion was inability to consent. After written informed consent, the participants were allowed to choose between the intervention group (IG) receiving a 90-min educational intervention and the control group (CG). The study was performed in accordance with the latest revision of the Helsinki Declaration and received approval by the Ethics Committee of the Medical Faculty Mannheim (reference no. 2016-580 N-MA).

\section{Data collection}

Participants of the IG were asked to complete a paperbased questionnaire and a short simulation test after study inclusion 2-4 weeks before the educational intervention (baseline $=\mathrm{t} 0$ ) and 8-12 weeks after the educational intervention at a regular visit (follow-up $=\mathrm{t} 1$ ). The CG completed the same questionnaires and simulation test as the IG also directly after study inclusion (t0) and about 8-12 weeks later during a regular visit ( $t 1)$.

To measure the beneficial effect of the intervention, the questionnaires comprised several outcome parameters of interest. Firstly, it contained visual analogue scales (VAS) regarding the patients' subjective self-assurance in using the emergency medication (range: 0 (very unsure) to 10 (very sure)) and the patients' willingness to always carry the emergency medication (range: 0 (not at all willing) to 10 (very willing)). Secondly, the individual depression and anxiety levels were assessed with the Hospital Anxiety and Depression Scale (HADS) [18]. This scale is a validated and a commonly used tool to assess patients' mental status and performs well in screening for anxiety or depression disorders [19]. Thirdly, participants were asked for the absolute one-time willingness-to-pay (WTP) for a complete cure of the insect venom allergy to measure the disease burden. Fourthly, a short quiz 
including questions on the emergency medication set (3 items), on medication that should be avoided during the VIT (1 item), and regarding further steps after administration of the emergency medication (1 item) (maximum total score 12 points) was also part of the questionnaires to quantify the individual state of knowledge (for details see Additional file 1: Table S1).

In addition to the questionnaire, a short simulation test was used to examine patients' ability to manage an acute sting reaction at $t 0$ and $t 1$. Therefore, the participant was confronted with a theoretical anaphylactic reaction after an insect sting and asked to tell in depth what to do step by step including demonstration of auto-injector use with an EAI training device. The performance was rated in a standardized fashion by AS, LS and MS together according to a predetermined point-based system with a maximum total score of 13 points (for details see Additional file 2: Table S2). Moreover, at baseline, the survey included questions on demographics and medical history and the physician documented the venom involved as well as the severity of reaction according to the Mueller 4-grade classification [20].

\section{Educational intervention}

The IG received a 90-min patient education intervention dealing with knowledge about anaphylaxis (trigger, pathogenesis, clinical features, course), information about insect stings (prevalence, differentiation of bees and wasps, sting prevention), and sting reaction management (components of the emergency kit, how to correctly use the kit for self-treatment, need for emergency medical attention, emergency action plan). Finally, the administration of the EIA was demonstrated and practiced in detail with the participants using training devices. Subsequently and during the intervention, participants were encouraged to ask questions. The training was held by two senior residents of the Department of Dermatology, Venereology and Allergology at the University Medical Center Mannheim (PD Dr. ML. Schaarschmidt and Prof. Dr. A. Schmieder), both experienced in the field for years. The intervention was offered 3 times between August and October 2016 with a median of $n=8$ (range: $7-10$ ) participants.

\section{Statistical analyses}

GraphPad Software (GraphPad Software, Inc., La Jolla, CA 92,037 USA) and IBM SPSS Statistics (Version 25 for Windows, IBM Germany, Ehningen, Germany) were used for analyses. If Gaussian distribution was confirmed with the d'Agostino and Pearson omnibus normality test, statistically significant differences for continuous parameters were examined by unpaired t-tests. For all continuous parameters without Gaussian distribution, the Mann-Whitney test was performed. For Categorial variables the Chi Square test was used as indicated. Analyses of covariance were conducted to compare differences in the outcome variables $(\mathrm{t} 1-\mathrm{t} 0)$ between the 2 arms (covariate=baseline values of the respective variable). Data were analyzed by using intention-to-treat analysis. Missing values at $\mathrm{t} 1$ were estimated by using "last observation carried forward" (LOCF). Significance was assumed at $\mathrm{p}<0.05$. Effect size $>0.1$ suggests a weak effect, $>0.25$ a medium effect, and $>0.4$ a strong effect.

\section{Results \\ Participant characteristics}

In total, 57 patients gave written informed consent. One patient had to be excluded due to a largely incomplete questionnaire and a second patient because there was no evidence of IgE-mediated sensitization to the venom of the culprit insect (skin test, specific IgE test as well as basophil activation test were negative). Thus, 55 participants (54.5\% female) were included in the final analysis (regarding baseline characteristics of the whole study cohort see also Schaarschmidt et al. [21] and Schoeben et al. [22]). 25 patients were part of the IG (52.0\% females) and 30 part of the CG (56.7\% females; Table 1). The mean age (IG: 55.9 years, CG: 52.0 years) and the mean disease duration (IG: 5.0 years, CG: 5.3 years) were comparable between the groups. Furthermore, the severity of anaphylaxis did not differ significantly between the arms. The main allergen reported was wasp venom (IG: $84.0 \%$, CG: $80.0 \%$ ) and most participants were currently on VIT (IG: $72.0 \%$, CG: $90.0 \%)$. The duration of VIT did not differ significantly between the groups (IG: 33.6 months, CG: 23.5 months).

\section{Pre-post comparison of outcome parameters}

\section{Subjective self-assurance in using the emergency medication}

At $\mathrm{t} 0$, mean values of subjective self-assurance did not differ significantly between the IG and the CG (IG $(\mathrm{n}=25): 6.1$ vs. CG $(\mathrm{n}=30): 7.1, \mathrm{p}=0.109)$. At $\mathrm{t} 1$ subjective self-assurance had significantly increased for both arms (IG $(n=23)$ : increase to 8.7 at $t 1, p<0.0001$; CG $(n=27)$ : increase to 8.0 at $t 1, p=0.006$; Fig. 1a). However, the IG showed a statistically significantly higher gain in self-assurance than the CG at follow-up (differences t1 to t0 IG - difference t1 to t0 $\mathrm{CG}=1.09$ (95\% confidence interval $(95 \% \mathrm{CI})=0.5 ; 1.7), \mathrm{p}=0.001$; Table 2).

\section{Willingness to always carry the emergency medication}

Mean willingness to always carry the emergency medication was comparable between the groups at baseline (IG $(\mathrm{n}=25): 7.1$ vs. CG $(\mathrm{n}=30): 8.2, \mathrm{p}=0.149$; Fig. 1b). Neither the IG nor the CG showed a significant 
Table 1 Baseline characteristics of the study cohort

\begin{tabular}{|c|c|c|c|c|}
\hline & $\begin{array}{l}\text { Total } \\
n=55\end{array}$ & $\begin{array}{l}\text { Intervention Group } \\
\mathrm{n}=\mathbf{2 5}\end{array}$ & $\begin{array}{l}\text { Control Group } \\
n=30\end{array}$ & p \\
\hline Females, n (\%) & $30(54.5)$ & $13(52.0)$ & $17(56.7)$ & $0.739^{\mathrm{a}}$ \\
\hline \multicolumn{5}{|l|}{ Age (years) } \\
\hline $\begin{array}{l}\text { Mean } \pm S D \\
\text { Min-max }\end{array}$ & $\begin{array}{l}53.8 \pm 12.1 \\
23-77\end{array}$ & $\begin{array}{l}55.9 \pm 13.4 \\
23-77\end{array}$ & $\begin{array}{l}52 \pm 10.8 \\
35-75\end{array}$ & $0.236^{b}$ \\
\hline \multicolumn{5}{|l|}{ Disease duration (years) } \\
\hline $\begin{array}{l}\text { Mean } \pm S D \\
\text { Min-max }\end{array}$ & $\begin{array}{l}5.1 \pm 6.1 \\
1-30\end{array}$ & $\begin{array}{l}5 \pm 3.8 \\
1-15\end{array}$ & $\begin{array}{l}5.3 \pm 7.6 \\
1-30\end{array}$ & $0.326^{a}$ \\
\hline \multicolumn{5}{|l|}{ Venom involved, $\mathrm{n}(\%)$} \\
\hline $\begin{array}{l}\text { Honeybee } \\
\text { Wasp } \\
\text { Honeybee and wasp }\end{array}$ & $\begin{array}{l}7(12.7) \\
45(81.8) \\
3(5.5)\end{array}$ & $\begin{array}{l}2(8.0) \\
21(84.0) \\
2(8.0)\end{array}$ & $\begin{array}{l}5(16.7) \\
24(80.0) \\
1(3.3)\end{array}$ & $0.503^{c}$ \\
\hline \multicolumn{5}{|c|}{ Severity of reaction, $\mathrm{n}(\%)$} \\
\hline $\begin{array}{l}\text { Mueller grade I } \\
\text { Mueller grade II } \\
\text { Mueller grade III } \\
\text { Mueller grade IV }\end{array}$ & $\begin{array}{l}6(10.9) \\
25(45.5) \\
20(36.4) \\
4(7.3)\end{array}$ & $\begin{array}{l}2(8.0) \\
11(44.0) \\
9(36.0) \\
3(12.0)\end{array}$ & $\begin{array}{l}4(13.3) \\
14(46.7) \\
11(36.7) \\
1(3.3)\end{array}$ & $0.618^{c}$ \\
\hline \multicolumn{5}{|c|}{ Venom immune therapy status, $\mathrm{n}(\%)$} \\
\hline $\begin{array}{l}\text { Currently ongoing } \\
\text { Completed } \\
\text { Intended } \\
\text { Not intended }\end{array}$ & $\begin{array}{l}45(81.8) \\
2(3.6) \\
3(5.5) \\
5(9.1)\end{array}$ & $\begin{array}{l}18(72.0) \\
1(4.0) \\
3(12.0) \\
3(12.0)\end{array}$ & $\begin{array}{l}27(90.0) \\
1(3.3) \\
0(0) \\
2(6.7)\end{array}$ & $0.205^{c}$ \\
\hline \multicolumn{5}{|c|}{ Venom immune therapy duration (months) } \\
\hline $\begin{array}{l}\text { Mean } \pm S D \\
\text { Min-max }\end{array}$ & $\begin{array}{l}27.6 \pm 26.1 \\
1-120\end{array}$ & $\begin{array}{l}33.6 \pm 33.6 \\
1-120\end{array}$ & $\begin{array}{l}23.5 \pm 19.4 \\
1-60\end{array}$ & $0.569^{\mathrm{a}}$ \\
\hline
\end{tabular}

Differences were tested for significance with ${ }^{\text {a }}$ Mann-Whitney-U-Test, ${ }^{b}$ unpaired t-test or ${ }^{\mathrm{c}}$ Chi-square test

Max: maximum; min: minimum; n: number; SD: standard deviation

higher willingness to always carry the emergency medication at follow-up (IG $(\mathrm{n}=23)$ : increase to 7.3 at $\mathrm{t} 1, \mathrm{p}=0.470$; $\mathrm{CG}(\mathrm{n}=27)$ : increase to 8.3 at $\mathrm{t} 1, \mathrm{p}=0.47$; difference IG-difference $\mathrm{CG}=-0.26(95 \% \mathrm{CI}=-1.2$; $0.6), \mathrm{p}=0.560$; Table 2).

\section{Depression and anxiety}

There was no significant difference regarding the depression subscale (IG $(n=25): 3.7$ vs. CG $(n=30): 3.6$, $\mathrm{p}=0.915$; Fig. $1 \mathrm{c})$ or the anxiety subscale (IG $(\mathrm{n}=25): 5.4$ vs. CG $(n=30)$ : 5.0, $p=0.723$; Fig. 1d) between the IG and the CG at t0. Neither depression scores (IG $(n=23)$ : decrease to 3.0 at $t 1, p=0.163$; CG $(n=28)$ : decrease to 3.3 at $\mathrm{t} 1, \mathrm{p}=1.000$; difference IG minus difference $\mathrm{CG}=-0.50(95 \% \mathrm{CI}=-1.4 ; 0.4), \mathrm{p}=0.288$; Table 2) nor anxiety scores (IG $(\mathrm{n}=23)$ : decrease to 4.7 at $\mathrm{t} 1$, $\mathrm{p}=0.235$; CG $(\mathrm{n}=28)$ : decrease to 4.6 at $\mathrm{t} 1, \mathrm{p}=0.810$; difference IG minus difference $\mathrm{CG}=-0.43 \quad(95 \%$ $\mathrm{CI}=-1.7 ; 0.8), \mathrm{p}=0.488$; Table 2 ) improved significantly at follow-up in both arms.

\section{Willingness-to-pay}

The mean one-time willingness to pay for cure did not differ significantly between the IG and the CG at t0
(IG $(\mathrm{n}=13): 896 €$ vs. CG $(\mathrm{n}=20): 2268 €, \mathrm{p}=0.222$; Fig. 1e). The amount of money participants were willing to pay barely changed at follow up (IG $(\mathrm{n}=15)$ : increase to $1437 €$ at t1, $\mathrm{p}=0.698$; CG $(\mathrm{n}=22)$ : decrease to $2264 €$ at $\mathrm{t} 1, \mathrm{p}=0.066$; difference IG minus difference $\mathrm{CG}=-234.76 €(95 \% \mathrm{CI}=-667.9 ; 198.4), \mathrm{p}=0.277$; Table 2).

\section{Knowledge quiz}

There was no difference in knowledge between the IG and CG at baseline (IG $(n=25): 7.7$ vs. CG $(n=30)$ : 7.1, $\mathrm{p}=0.209$; Fig. 1f). At $\mathrm{t} 1$, individual knowledge had not significantly increased for both arms (IG $(\mathrm{n}=23)$ : increase to 8.3 at $\mathrm{t} 1, \mathrm{p}=0.164$; CG $(\mathrm{n}=28)$ : increase to 8.0 at $\mathrm{t} 1, \mathrm{p}=0.423$; difference IG minus difference $\mathrm{CG}=0.42(95 \% \mathrm{CI}=0.3 ;-0.4), \mathrm{p}=1.211$; Table 2). Mean scores of the individual questions did not differ between the groups at $\mathrm{t} 0$. However, at $\mathrm{t} 1$ the IG showed a significantly higher score regarding the question on medication that should be avoided during the VIT compared to the CG (IG: $0.36 \pm 0.58$ vs. CG: $0.11 \pm 0.32, \mathrm{p}=0.05$; Additional file 3: Table S3). 


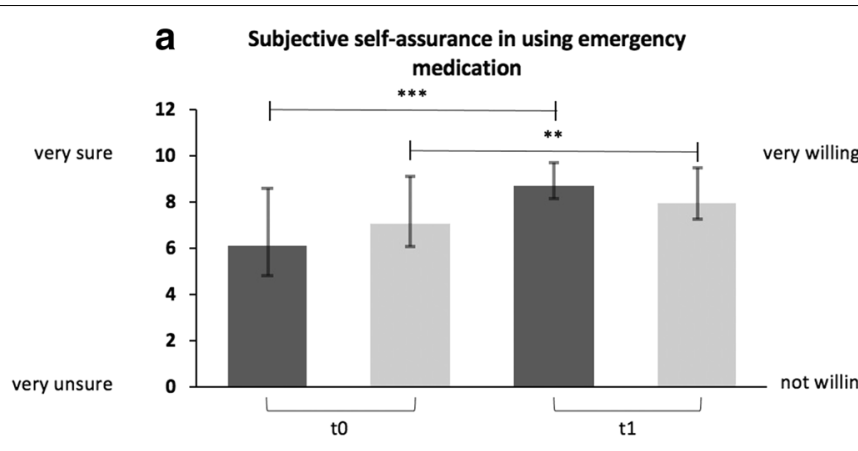

\section{b Willingness to always carry emergency medication}
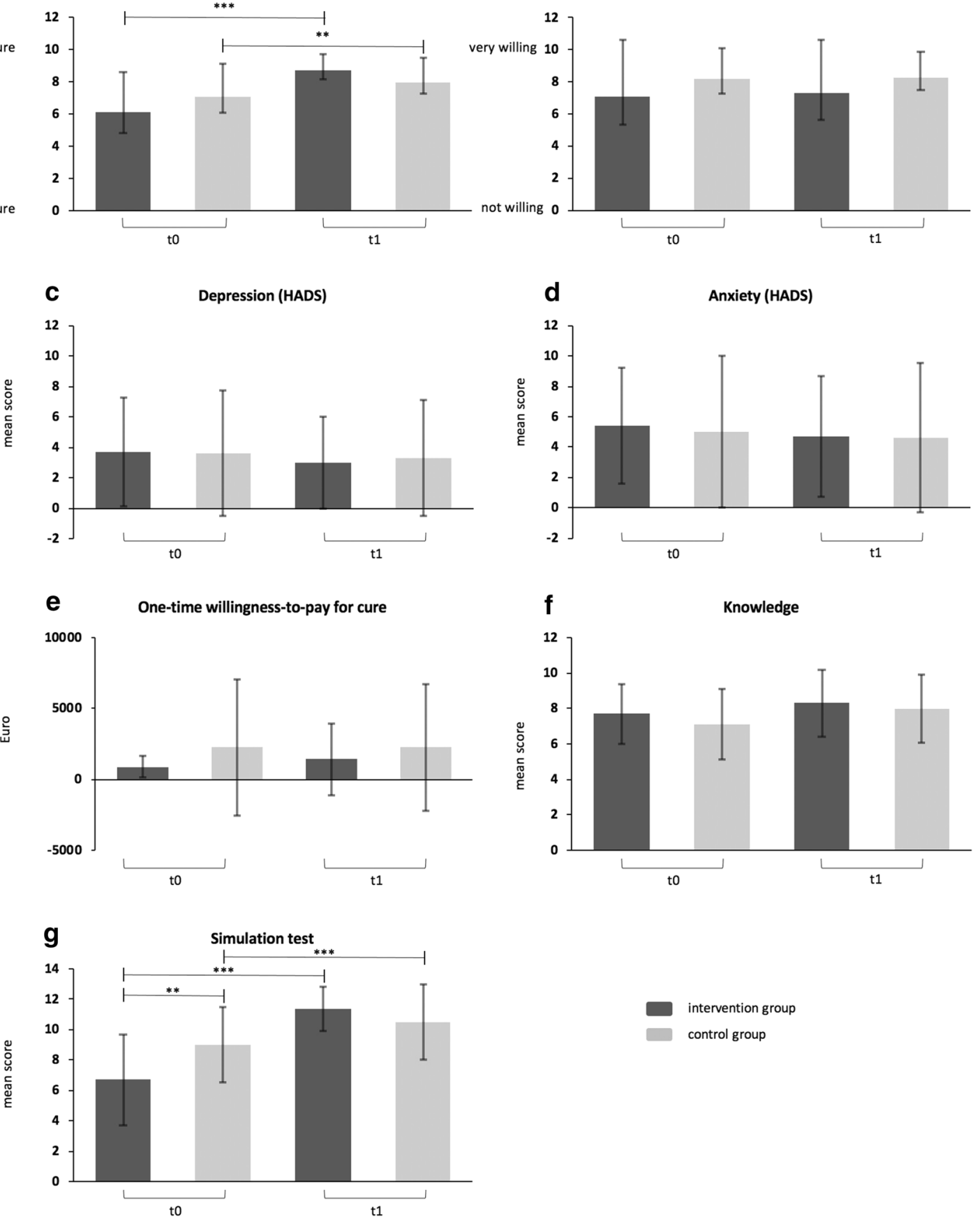

Fig. 1 Pre (t0) - post (t1) comparison of the outcome parameters as well as comparison between the intervention and the control group. a Mean subjective self-assurance in using the emergency medication on a visual analogue scale (VAS) (range: 0 (very unsure) to 10 (very sure)). b Mean willingness to always carry the emergency medication on a VAS (range: 0 (not willing) to 10 (very willing)). c Mean depression level and $\mathbf{d}$ mean anxiety level regarding the Hospital Anxiety and Depression Scale (HADS). e Mean absolute one-time willingness to pay for complete cure (in Euro). f Mean score reached in the Knowledge-quiz (maximum score: 12 points). $\mathbf{g}$ Mean score achieved at the simulation test dealing with the patients' ability to manage an acute sting reaction (maximum score: 13 points). ${ }^{* *} p \leq 0.01,{ }^{* * *} p \leq 0.001$. Bars: Means with standard deviation 
Table 2 Outcome variables by using Analyses of covariance (covariate $=$ baseline values) of differences between baseline (t0) and follow-up (t1) for the Intervention Group and the Control Group

\begin{tabular}{|c|c|c|c|c|c|}
\hline \multirow[t]{3}{*}{ Outcome variables } & Intervention Group (IG) & $\begin{array}{l}\text { Control Group } \\
\text { (CG) }\end{array}$ & IG- CG & \multirow[t]{3}{*}{ p } & \multirow[t]{3}{*}{ Effect size (r) } \\
\hline & $\begin{array}{l}\text { Estimated marginal means } \\
\text { and } 95 \% \mathrm{Cl} \text { of differences } \\
\text { (t1-t0) }\end{array}$ & $\begin{array}{l}\text { Estimated marginal means } \\
\text { and } 95 \% \mathrm{Cl} \text { of differences } \\
\text { (t1-t0) }\end{array}$ & $\begin{array}{l}\text { Estimated marginal means } \\
\text { and } 95 \% \mathrm{Cl} \text { of differences } \\
((\mathrm{IG} \mathrm{t} 1-\mathrm{t} 0)-(\mathrm{CG} \mathrm{t} 1-\mathrm{t} 0))\end{array}$ & & \\
\hline & Mean $(95 \% \mathrm{CI})$ & Mean $(95 \% \mathrm{Cl})$ & Mean $(95 \% \mathrm{Cl})$ & & \\
\hline Subjective self-assurance ${ }^{a}$ & $2.141(1.71 ; 2.57)$ & $1.049(0.66 ; 1.44)$ & $1.092(0.50 ; 1.68)$ & 0.001 & 0.457 \\
\hline $\begin{array}{l}\text { Willingness to carry } \\
\text { medication }^{b}\end{array}$ & $0.112(-0.54 ; 0.77)$ & $0.373(-0.22 ; 0.97)$ & $-0.261(-1.19 ; 0.63)$ & 0.560 & 0.081 \\
\hline Depression (HADS) & $-0.511(-1.20 ; 0.18)$ & $-0.008(-0.64 ; 0.63)$ & $-0.503(-1.44 ; 0.44)$ & 0.288 & 0.147 \\
\hline Anxiety (HADS) & $-0.543(-1.45 ; 0.37)$ & $-0.114(-0.95 ; 0.72)$ & $-0.429(-1.66 ; 0.81)$ & 0.488 & 0.096 \\
\hline One-time WTPC & $41.055(-294 ; 376.1)$ & $275.815(6.64 ; 545.0)$ & $-234.76(-667.91 ; 198.4)$ & 0.277 & 0.198 \\
\hline Knowledge quiz & $0.555(-0.03 ; 1.14)$ & $0.138(-0.40 ; 0.67)$ & $0.417(-0.38 ; 1.21)$ & 0.288 & 0.144 \\
\hline Simulation test & $3.673(2.86 ; 4.49)$ & $2.106(1.37 ; 2.84)$ & $1.567(0.43 ; 2.71)$ & 0.008 & 0.357 \\
\hline
\end{tabular}

$\mathrm{Cl}$ : confidence interval. Effect size: $>0.1$ weak effect, $>0.25$ medium effect, $>0.4$ strong effect. HADS: Hospital Anxiety and Depression Scale. $€$ : Euro. t0: baseline. t1: follow-up. Significant findings are highlighted in italics

a Subjective self-assurance in using the emergency medication

b Willingness to always carry the emergency medication

c Absolute one-time willingness-to-pay (WTP) for a complete cure

\section{Simulation test}

The CG performed significantly better in the simulation test than the IG at t0 (IG $(n=25): 6.7$ vs. CG $(n=30): 9.0$, $\mathrm{p}=0.004$; Fig. 1g). At follow up, both arms performed significantly better than at t0 (IG $(n=24)$ : increase to 11.4 at $\mathrm{t} 1, \mathrm{p}<0.0001$; CG $(\mathrm{n}=28)$ : increase to 10.5 at $\mathrm{t} 1, \mathrm{p}=0.0002)$. However, the IG showed a significantly higher increase than the CG from to to t1 (difference IG minus difference $\mathrm{CG}=1.57(95 \% \mathrm{CI}=0.4 ; 2.7), \mathrm{p}=0.008$; Table 2).

\section{Discussion}

This prospective single-center pilot study provides data on effects of a structured 90-min educational intervention for patients with insect sting allergy. The intervention included relevant knowledge on insect sting allergy as well as training on practical skills on how to manage anaphylaxis and use the emergency medication correctly. It was performed by allergists in small patient groups in an outpatient setting.

Trained patients and interestingly also the CG had statistically significant benefits with respect to subjective self-assurance in using the emergency medication and patients' ability to manage an acute sting reaction after study participation. We conclude that outcome improvements may partly be attributable to the repeated testing even in the absence of any education. Furthermore, we cannot rule out that participants of the CG have undertaken self-training as well after study participation at baseline. However, the IG showed a higher gain in self-assurance and ability to manage an acute reaction in a simulation exercise at follow-up, which suggests a possible beneficial effect of the intervention itself regarding these outcomes. Brockow et al. developed a standardized 6-h educational intervention for patients at risk for anaphylaxis. At follow-up, the patient education program was significantly more effective at improving practical emergency management skills compared to no intervention [17]. Gain in selfassurance in using the emergency medication is a very important aspect because uncertainty about the correct use has been reported repeatedly [16, 23]. In a study by Warren et al., not even $60 \%$ of patients expressed confidence in their ability to use their EAI correctly [23]. In the mentioned study, $52 \%$ of adult participants indicated that no EAI was used during their most severe anaphylactic reaction of which $21 \%$ expressed lack of knowledge on when or how to administer epinephrine as leading reason [23]. According to a review on pitfalls in the use of epinephrine for anaphylaxis, inadequate education of patients or providers and uncertainty about when or how to administer epinephrine are frequently reported. However, the most common problem was lack of autoinjector availability [16]. Looking at the willingness to always carry the emergency medication in our study, neither the IG nor the CG showed a significant enhancement at follow-up. As anaphylaxis is potentially life threatening, a prompt availability of medication is essential [16, 24]. A failure or delay in administration of adrenaline may increase the risk of death according 
to fatality register studies [13]. Nevertheless, noncompliance in carrying the emergency medication is stated repeatedly $[2,9,10,14,16,17,23]$. However, high rates of willingness to carry the medication were observed at t0 in both of our study arms. Thus, we assume that our patients already paid attention to that necessity before study participation and therefore the effect of the intervention regarding this issue was not significant.

We found no significant improvement regarding depression and anxiety measurements and disease burden (WTP) in both study arms. This observation might reflect the fact that disease related psychological strain was not specifically focused on during our brief 90-min training and psychologists were not involved. However, also Brockow et al., who conducted a longer education program for patients at risk for anaphylaxis with psychologists as part of the team, did not show a significant improvement of anxiety and depression scores of adult participants after the intervention [17]. Furthermore, no significant improvement of disease specific knowledge could be achieved through our 90-min education. In contrast, the more extensive education aforementioned program for the management of anaphylaxis was significantly more effective at improving knowledge compared to no intervention [17]. Improving knowledge seems to be of particular importance. Thus, a systematic review on gaps in anaphylaxis management revealed lack of knowledge as one of the major themes [25]. We suggest that the short intervention period of our study and the monodisciplinary team might be the reason for our negative result. It is conceivable that trained personnel specifically dedicated to effective communication and education (e.g. psychologists, pedagogues) as part of the team might have made a significant difference in this outcome parameter.

There are limitations to our study. The monocentric design and the restricted number of participants limit the generalizability of the results. Due to the limited cohort size, statistical significant differences between subgroups might have been missed or overestimated. However, clinical significance is a decision based on the practical value or relevance of the intervention, and this does not necessarily involve statistical significance as an initial criterion [26]. Additionally, patients with severe reactions (Mueller grade IV) and patients allergic to bee venom were not well represented in the study population. As many beekeepers (a considerable part of the bee allergic population) and patients who experienced more severe reactions are likely to be more aware of the risk and have different habits, the results may not be completely applicable to that subpopulations. Furthermore, we did not investigate long-term effects of the intervention. The lack of randomization is definitely an additional limitation, as patients willing to accept a 90-min training are likely to pay more attention to the management of an acute reaction and probably saw a higher need for improvement, compared to patients not interested in the training. Consistently, the ability to manage an acute sting reaction was significantly better in the CG at to than in the IG, while mean values of subjective self-assurance, willingness to always carry the emergency medication, depression and anxiety subscales, willingness to pay and knowledge scores did not differ significantly between the two groups. Moreover, a lack of blinding of the investigator needs to be noted as limitation.

Furthermore, it has to be mentioned, that the recommendations for the components of the "emergency set for self-help "vary between countries. First line therapy for anaphylactic sting reactions is intramuscular adrenaline, while there is no high-quality evidence to confirm the effectiveness of antihistamines and glucocorticoids in the treatment of anaphylaxis [27]. Thus, in several countries only self-injectable epinephrine is recommended as medical therapy that a patient should carry with them for self-medication of anaphylactic reactions. It is also still a debated issue whether EAI should be carried during and after VIT. In general, patients are protected after reaching the maintenance dose. However, German guidelines recommend carrying an emergency kit after the end of VIT [28].

Overall, our 90-min educational program had a positive impact on the participants' empowerment to manage an acute sting reaction. It has been shown that patients often have difficulties to recall information provided during brief doctors' visits [29] and counselling is often neglected [30]. Furthermore, patients seldom express their concerns and often do not ask questions about their diagnosis or treatment during consultations [31, 32]. Educational interventions aim to empower patients in self-management of their disease [33] and an increase in disease knowledge is associated with better therapy adherence and higher patient satisfaction [34, 35]. A recent US study on adults, adolescents and parents of children who had been prescribed an EAI revealed that $61 \%$ of participants desired more effective patient education and $47 \%$ desired more time dedicated to patient education during the physician visit to improve clinical anaphylaxis management [23]. Beneficial effects of educational programs have been proven for several disorders, e.g. atopic eczema [36], bronchial asthma [37] and anaphylaxis [17]. 


\section{Conclusion}

We have shown that patients who are willing to invest $90 \mathrm{~min}$ in a patient education intervention benefit by an increased subjective and objective empowerment to manage an acute sting reaction.

Based on the data presented here, we believe that brief educational programs for patients with insect sting allergy should be routinely offered to improve patient care.

We think it is not only the responsibility of providers to prescribe emergency medication when indicated but also to train patients with insect sting allergy in its correct use, proper management of a reaction, and to remind patients of the importance of carrying the medication. We recommend a periodical patient education including a simulation training for every patient with insect sting allergy.

\section{Supplementary Information}

The online version contains supplementary material available at https://doi. org/10.1186/s13223-021-00524-7.

Additional file 1: Table S1. Knowledge quiz (maximum total score 12 points). Additional details about the "knowledge quiz" are provided.

Additional file 2: Table S2. Simulation test (maximum total score 13 points). Additional details about the "Simulation test" are provided.

Additional file 3: Table S3. Differences in answering the individual questions of the knowledge quiz between the intervention and the control group at t0 and t1. Differences in answering the individual questions of the knowledge quiz between the IG and CG are provided.

\section{Abbreviations}

CG: Control group; Cl: Confidence interval; EAl: Epinephrine auto-injectors; HADS: Hospital Anxiety and Depression Scale; IgE: Immunoglobulin E; IG: Intervention group; LOCF: Last observation carried forward; max: Maximum; min: Minimum; n: Number; SD: Standard deviation; t0: Baseline; t1: Follow-up; VAS: Visual analogue scales; VIT: Venom immunotherapy; WTP: Willingness-to-pay.

\section{Acknowledgements}

We thank the physicians and nursing staff of the Department of Dermatology, University Medical Center Mannheim, for support with patient recruitment.

\section{Authors' contributions}

LSS and MLS: conception and design of the study, data collection and statistical analysis, wrote the draft of the manuscript. NM: statistical analysis and data interpretation. CB: conception and design of the study. AS: conception and design of the study, data collection and statistical analysis. All authors read and approved the final manuscript.

\section{Funding}

Open Access funding enabled and organized by Projekt DEAL.

\section{Availability of data and materials}

The datasets used and analysed during the current study are available from the corresponding author on reasonable request.

\section{Ethics approval and consent to participate}

The study was performed in accordance with the latest revision of the Helsinki Declaration and received approval by the Ethics Committee of the Medical Faculty Mannheim (reference no. 2016-580N-MA). Written informed consent was obtained from all participants.

\section{Consent for publication}

Not applicable.

\section{Competing interests}

Dr. Schaarschmidt received financial support for participation in conferences from ALK-Abello. Prof. Schmieder received financial support for participation in conferences from MEDA. Mrs. Schoeben, Mrs. Mohr and Mrs. Bubak have no competing interests to declare.

\section{Author details}

${ }^{1}$ Department of Dermatology, University Medical Center Mannheim, Heidelberg University, Theodor-Kutzer-Ufer 1-3, 68135 Mannheim, Germany.

${ }^{2}$ Institute for Health Services Research in Dermatology and Nursing (IVDP),

University Medical Center Hamburg-Eppendorf, Hamburg, Germany.

Received: 18 October 2020 Accepted: 8 February 2021

Published online: 25 February 2021

\section{References}

1. Ring J, Beyer K, Biedermann T, Bircher A, Duda D, Fischer J, et al. Guideline for acute therapy and management of anaphylaxis: S2 Guideline of the German Society for Allergology and Clinical Immunology (DGAKI), the Association of German Allergologists (AeDA), the Society of Pediatric Allergy and Environmental Medicine (GPA), the German Academy of Allergology and Environmental Medicine (DAAU), the German Professional Association of Pediatricians (BVKJ), the Austrian Society for Allergology and Immunology (OGAI), the Swiss Society for Allergy and Immunology (SGAI), the German Society of Anaesthesiology and Intensive Care Medicine (DGAI), the German Society of Pharmacology (DGP), the German Society for Psychosomatic Medicine (DGPM), the German Working Group of Anaphylaxis Training and Education (AGATE) and the patient organization German Allergy and Asthma Association (DAAB). Allergo J Int. 2014;23:96-112.

2. Confino-Cohen R, Melamed S, Goldberg A. Debilitating beliefs, emotional distress and quality of life in patients given immunotherapy for insect sting allergy. Clin Exp Allergy. 1999;29:1626-31.

3. Panesar SS, Javad S, de Silva D, Nwaru BI, Hickstein L, Muraro A, et al. The epidemiology of anaphylaxis in Europe: a systematic review. Allergy. 2013;68:1353-61.

4. Turner PJ, Campbell DE, Motosue MS, Campbell RL. Global Trends in Anaphylaxis Epidemiology and Clinical Implications. J Allergy Clin Immunol Pract. 2020;8:1169-76.

5. Antonicelli L, Bilo MB, Bonifazi F. Epidemiology of Hymenoptera allergy. Curr Opin Allergy Clin Immunol. 2002;2:341-6.

6. Golden DB, Breisch NL, Hamilton RG, Guralnick MW, Greene A, Craig TJ, et al. Clinical and entomological factors influence the outcome of sting challenge studies. J Allergy Clin Immunol. 2006;117:670-5.

7. Dhami S, Zaman H, Varga EM, Sturm GJ, Muraro A, Akdis CA, et al. Allergen immunotherapy for insect venom allergy: a systematic review and metaanalysis. Allergy. 2017;72:342-65.

8. Oude Elberink JN, van der Heide S, Guyatt GH, Dubois AE. Analysis of the burden of treatment in patients receiving an EpiPen for yellow jacket anaphylaxis. J Allergy Clin Immunol. 2006;118:699-704.

9. Mullins RJ. Anaphylaxis: risk factors for recurrence. Clin Exp Allergy. 2003;33(8):1033-40.

10. Goldberg A, Confino-Cohen R. Insect sting-inflicted systemic reactions: attitudes of patients with insect venom allergy regarding after-sting behavior and proper administration of epinephrine. J Allergy Clin Immunol. 2000;106:1184-9.

11. Huang S-W. A survey of Epi-PEN use in patients with a history of anaphylaxis. Journal of Allergy and Clinical Immunology. 1998;102:525-6.

12. Gold MS, Sainsbury R. First aid anaphylaxis management in children who were prescribed an epinephrine autoinjector device (EpiPen). J Allergy Clin Immunol. 2000;106(1 Pt 1):171-6.

13. Pumphrey RS. Lessons for management of anaphylaxis from a study of fatal reactions. Clin Exp Allergy. 2000;30:1144-50.

14. Sanchez J. How often patients carry epinephrine in real life? Anaphylaxis. 2013;60(4):168-71. 
15. Worm M, Eckermann O, Dolle S, Aberer W, Beyer K, Hawranek T, et al. Triggers and treatment of anaphylaxis: an analysis of 4,000 cases from Germany. Austria and Switzerland Dtsch Arztebl Int. 2014;111:367-75.

16. Cohen MB, Saunders SS, Wise SK, Nassif S, Platt MP. Pitfalls in the use of epinephrine for anaphylaxis: patient and provider opportunities for improvement. Int Forum Allergy Rhinol. 2017;7:276-86.

17. Brockow K, Schallmayer S, Beyer K, Biedermann T, Fischer J, Gebert N, et al. Effects of a structured educational intervention on knowledge and emergency management in patients at risk for anaphylaxis. Allergy. 2015;70:227-35

18. Zigmond AS, Snaith RP. The hospital anxiety and depression scale. Acta Psychiatr Scand. 1983;67:361-70

19. Bjelland I, Dahl AA, Haug TT, Neckelmann D. The validity of the Hospital Anxiety and Depression Scale: An updated literature review. J Psychosom Res. 2002;52:69-77.

20. Mueller HL. Diagnosis and Treatment of Insect Sensitivity. J Asthma Res. 1966;3:331-3.

21. Schaarschmidt M-L, Gutknecht M, Schoeben L, Schmieder A. Disease burden, psychological well-being and attitudes regarding the set of emergency medication in adults with insect venom allergy. Int Arch Allergy Immunol. 2018;176:150-6.

22. Schoeben LS, Bubak C, Schaarschmidt ML, Schmieder A. Sex differences in adults with insect venom allergy regarding psychological distress, attitudes toward the emergency medication, and factual knowledge about the disease. Int Arch Allergy Immunol. 2020;181:529-35.

23. Warren CM, Zaslavsky JM, Kan K, Spergel JM, Gupta RS. Epinephrine autoinjector carriage and use practices among US children, adolescents, and adults. Ann Allergy Asthma Immunol. 2018;9:89.

24. Golden DB. Anaphylaxis to insect stings. Immunol Allergy Clin North Am. 2015;35:287-302.

25. Kastner M, Harada L, Waserman S. Gaps in anaphylaxis management at the level of physicians, patients, and the community: a systematic review of the literature. Allergy. 2010;65:435-44.

26. Fethney J. Statistical and clinical significance, and how to use confidence intervals to help interpret both. J Aust Crit Care. 2010;23:93-7.

27. Bilò MB, Cichocka-Jarosz E, Pumphrey R, Oude-Elberink JN, Lange J, Jakob T, et al. Self-medication of anaphylactic reactions due to Hymenoptera stings-an EAACI Task Force Consensus Statement. Allergy. 2016;71:931-43
28. Przybilla B, Ruëff F, Walker A, Räwer HC, Aberer W, Bauer CP, et al. Diagnose und Therapie der Bienen und Wespengiftallergie. Allergo J. 2011;20:318-39.

29. Braddock $\mathrm{CH}$ 3rd. The emerging importance and relevance of shared decision making to clinical practice. Med Decis Making. 2010;30(Suppl 5):5-7.

30. Deccache A, Aujoulat I. A European perspective: common developments, differences and challenges in patient education. Patient Educ Couns. 2001;44:7-14

31. Barry CA, Bradley CP, Britten N, Stevenson FA, Barber N. Patients' unvoiced agendas in general practice consultations: qualitative study. BMJ. 2000;320:1246-50.

32. Britten N, Stevenson FA, Barry CA, Barber N, Bradley CP. Misunderstandings in prescribing decisions in general practice: qualitative study. BMJ. 2000;320:484-8.

33. Williams LM, Alderman JE, Cussell G, Goldston J, Hamilton N, Lim AC, et al. Patient's self-evaluation of two education programs for age-related skin changes in the face: a prospective, randomized, controlled study. Clin Cosmet Investig Dermatol. 2011;4:149-59.

34. Bron MS, O'Neill J, Fogel I. Improving adherence to sertraline treatment: the effectiveness of a patient education intervention. Prim Care Companion J Clin Psychiatry. 2006:8:285-90.

35. See JA, Goh CL, Hayashi N, Suh DH, Casintahan FA. Optimizing the use of topical retinoids in Asian acne patients. J Dermatol. 2018;45:522-8.

36. Staab D, Diepgen TL, Fartasch M, Kupfer J, Lob-Corzilius T, Ring J, et al. Age related, structured educational programmes for the management of atopic dermatitis in children and adolescents: multicentre, randomised controlled trial. BMJ. 2006;332:933-8.

37. Szczepanski R, Jaeschke R, Spindler T, Ihorst G, Forster J. Preschoolers' and parents' asthma education trial (P2AET)-a randomized controlled study. Eur J Pediatr. 2010;169:1051-60.

\section{Publisher's Note}

Springer Nature remains neutral with regard to jurisdictional claims in published maps and institutional affiliations.

Ready to submit your research? Choose BMC and benefit from:

- fast, convenient online submission

- thorough peer review by experienced researchers in your field

- rapid publication on acceptance

- support for research data, including large and complex data types

- gold Open Access which fosters wider collaboration and increased citations

- maximum visibility for your research: over 100M website views per year

At BMC, research is always in progress.

Learn more biomedcentral.com/submissions 